\title{
REMOTE ADMINISTRATION OF BMS THROUGH ANDROID APPLICATION
}

\author{
Monika Rana ${ }^{1}$, Prateek Bindra², Manish Kumar Chauhan ${ }^{3}$ \\ ${ }^{1} P G$ Student M.Tech (ES), EECE Department, ITM University, Gurgaon, Haryana, India \\ ${ }^{2}$ Assistant Professor, EECE Department, ITM University, Gurgaon, Haryana, India \\ ${ }^{3} P G$ Student M.Tech (ES), EECE Department, ITM University, Gurgaon, Haryana, India
}

\begin{abstract}
SAN (Storage Area Network) is a committed high-speed network that interconnects data storage devices and multiple servers. It allows the device to appear like locally attached device to the operating system by enhancing storage devices which are accessible to server and consequently secures the manner in which the database connects with the server. Thus enabling design of portable devices that allow the user to control the building constants from remote places.[1][2][3] By gaining the access to control of building constants application like BMS (Building Management System) can be easily configured. BMS in actual is a microprocessor based electronic module or device which can be installed in a building to allow the user to operate, manage and measure real time data of various parameters. Data of the building can be accessed and modified through android app. The protocol used for communication between the app and web server is GPRS.[4][5] BMS is used to securely store and configure rules and parameters of an intelligent building like secured access-control, lighting and temperature etc.
\end{abstract}

Key Words: GPRS, SAN, Microcontroller, Industrial Appliance, Android, Smart building.

\section{INTRODUCTION}

SAN is a high performance network which provides communication among storage devices and computer systems. Building Management System built on the top of SANs provide file-level access along with block level operations. BMS is a computer system that can retrieve and analyses the pre-set parameters of building and control those parameters to meet the needs of end user.[6][7] Its inputs received such as temperature and humidity from temperature sensor and humidity sensor respectively and outputs, such as on/off commands issue from the remotely located server are passed onto outstations located in vicinity of the building. Programmer within the outstations after retrieving this information makes decisions for the necessary level of applied control. The multiple outstations are linked to each other and thus information is passed among them. In addition a modem is also connected to the system to allow remote access.[8][9] The control using the BMS depends upon the information received from the sensors and the manner in which programmer generate response to that information. For a precise and accurate control of parameters to its environment, BMS can be configured to alarm or to issue warnings on conditions and events that don't meet specifications or warn of individual items.

The purpose of a Building Management System (BMS) is to automate and take control of these operations in the most efficient way possible for the occupiers/business, within the constraints.[10] Building management through SAN enables centralized control facility from remote site for regulation of building parameters and simpler operation by programmed routine and functions, thereby reducing consumption of time and resources.
BMS ensures quicker troubleshooting by enabling faster response to the end users and technicians and improved indoor environment for living and working environments by control of the parameters such as temperature and humidity.

\section{BLOCK DIAGRAM}

The block diagram explains the communication between SAN and the Android App.

SAN (Storage Area Network)



Chart -1: Block Diagram of the project 
SAN includes both the electronic circuit i.e. Building Management Device (BMD) and the software part i.e. parser, server, database and the web server.

The BMD includes various analog and digital sensors for sensing different parameters like smoke, humidity, temperature, light intensity etc. The BMD is an ATmega32 microcontroller based device which analyzes and controls the basic building parameters. The device also monitors basic events and mishappenings which are unanticipated. The information received from different sensors is transformed into a packet and is this packet is transmitted by GPRS modem to the Server. The packet is then parsed and useful information is stored in MySQL database for further reference and for retrieval later on. A web server is created with access to localhost database; it may communicate with the Android Application for controlling the building constants along with provisions of other web services. [11]

An Android Application is created for TCP-IP Client-Server communication. The accuracy of transmitted data packet is controlled by TCP whereas the actual data transferred on the GPRS network is performed by IP.

\section{FLOW CHART/ALGORITHM}



Chart -2: Flow chart of Server side
The flow chart is divided into two parts, namely server side and client side.

Whenever we turned on the device the constant of all server is collected in a controller circuit which is connected to all sensors wired or wirelessly. After collecting all data from sensor in controller card, the controller card forms a packet of sensor data and sends it to the server through TCP-IP communication. The server receives the packet which is sent by controller card and parses the packet data and retrieves the information from the data packet. Server on process useful information like events of mishappenings and failures. This event data is stored into MySQL database which can be accessed when required. After retrieving all data from packet, server generates an acknowledgement and command set and sends it to client side.



Chart -3: Flow Chart of the Client side

The acknowledgement and command set sent by server is received at client side and parse the information from packet. Client verifies the data, whether the data received is same as the data from the sensors or not. If it is same, no changes were made else changes were implemented in the BMD and the status of the appliances is set accordingly.

\section{APPLICATION AREAS}

The Building Management Device has varying applications and multiple platforms like in airports, hospitals, industries and many more. This device can be easily installed in any building and it is good to go. It is capable of providing real time data and can reduce overall energy needs of a building making it energy efficient.[12] Thus providing a future proof and scalable building management system that optimizes and manage a wide range building services.

\section{ADVANTAGES \& LIMITATIONS}

The device designed enables visibility and centralized control of the building constants and has increased the level 
of security. It increases the value of the building whereas decreased running cost and maintenance economy by avoiding expensive failures.[13] BMD improves reliability and helps in conservation of energy. It ensures an easy way to detect an issue and to eliminate it. The system provides an improved security, fire and other emergency events.[14]

The control level through BMD is dependent upon the quality of information received from the sensors. If information received is not accurate, results may not be as per our requirements. The disadvantage of the system is that if some modifications are to be made, the software demands modification in every workstation.

\section{RESULT}

The Android Application is able to send data to the server and this parsed data is shown on the server's screen.

Results have been obtained from the sensors and the data has been successfully displayed on the server.

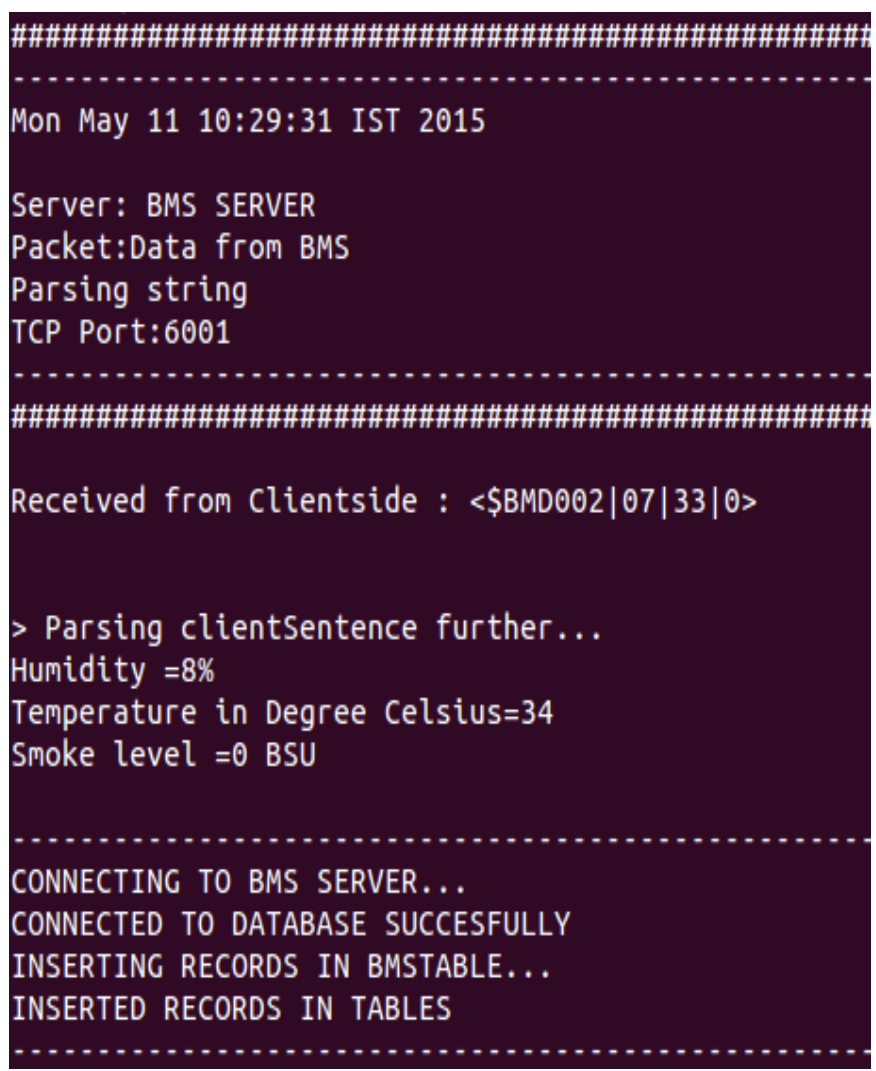

Chart -4: Screenshot of data displayed on server

\section{CONCLUSION AND FUTURE SCOPE}

The device can easily operate and manipulate the building services from remote places and manages the energy usage in the building.[15] This device has been successful in discarding the need of being in a confined area to control the building constants.

The sensor data can be acquired more precisely by using FreeRTOS which minimizes the delay between the tasks and achieves real time sensor information.

\section{ACKNOWLEDGEMENT}

I express my gratitude to professors, faculties and staff of Department of Electrical, Electronics \& Communication Engineering of ITM University, Gurgaon along with Xinoe Systems Private Limited by whose support and guidance I was able to complete my research work timely and unperturbedly.

\section{REFERENCES}

[1]. Krejcar, 0., Horkem, J. "Remote Access Of Building Management System On Windows Mobile Devices". Networking and Information Technology (ICNIT), 2010 International Conference on DOI: 10.1109/ICNIT.2010.5508449 Publication Year: 2010 , Page(s):560 - 564

[2]. Dengler, Sebastian; Awad, Abdalkarim; Dressler, Falko, "Sensor/Actuator Networks in Smart Homes for Supporting Elderly and Handicapped People." Advanced Information Networking and Applications Workshops, 2007, AINAW '07. 21st International Conference on, Volume 2, 21-23 May 2007, Page(s):863 - 868 .

[3]. Krejcar, 0., "PDPT framework - Building information system with wireless connected mobile devices", In Icinco 2006, 3rd International Conference on Infonnatics in Control, Automation and Robotics Insticc Press, Setubal, Portugal, pp. 162-167 (2006)

[4]. Kastner, W. ; Neugschwandtner, G. ; Soucek, S. ; Newmann, "Communication Systems for Building Automation and Control", H.M. Proceedings of the IEEE Volume: 93 , Issue: 6 DOI: 10.1109/JPROC.2005.849726 Publication Year: 2005 , Page(s): 1178 - 1203

[5]. Yu-Wei Huang; Shun-Chien Chang ; Chih-Hung Wu "GPRS-Based Embedded Remote Power Management System Network And Mobile Technology", Sensors for Industry Conference, 2005 DOI: 10.1109/SICON.2005.257878 Publication Year: 2005 , Page(s): 105 - 110

[6]. Jiang, Li, Da-You Liu, and Bo Yang, "Smart Home Research", Machine Learning and Cybernetics (2004). 15 Oct. 2007.

[7]. Yamazaki, T, "Beyond the Smart Home", Hybrid Information Technology, 2006. ICHIT'06. Vol 2. International Conference on, Volume 2, Nov. 2006 Page(s):350 - 355 .

[8]. Smitha, S.D. ; Chacko, F.M. "Intelligent Energy Management in Smart and Sustainable Buildings with Multi-agent Control System", Automation, Computing, Communication, Control and Compressed Sensing (iMac4s), 2013 International Multi-Conference on DOI: 10.1109/iMac4s.2013.6526406 Publication Year: 2013 , Page(s): $190-195$

[9]. F. Obayashi and Y. Tokunaga, "A Study of Building Energy Management Systems based of Multi Agents," in SICE annual Conference in Fukui, Fukui, Japan, 2003. 
[10]. Gao Manru; Su Wei ; Xue Lijun "Engineering design of intelligent building management system (IBMS)", Computer and Communication Technologies in Agriculture Engineering (CCTAE), 2010 International Conference On Volume: 1 DOI: 10.1109/CCTAE.2010.5544762 Publication Year: 2010, Page(s): 337 - 340

[11]. Yinbo Wu, “An Open Web-Based Integrated System For Intelligent Building”, Mechatronic Sciences, Electric Engineering and Computer (MEC), Proceedings 2013 International Conference on DOI: 10.1109/MEC.2013.6885068 Publication Year: 2013 , Page(s): $173-176$

[12]. Anjos, D.; Carreira, P.; Francisco, A.P. "Real-Time Integration of Building Energy Data", Big Data (BigData Congress), 2014 IEEE International Congress on, On page(s): $250-257$

[13]. Borkowski, P. ; Pawlowski, M. ; Makowiecki, T. "Economical Aspects of Building Management Systems Implementation", PowerTech, 2011 IEEE Trondheim DOI: 10.1109/PTC.2011.6019439 Publication Year: 2011, Page(s): $1-6$

[14]. Gabriele, T. ; Pantoli, L. ; Stornelli, V. ; Chiulli, D. ; Muttillo, M. "Smart Power Management System For Home Appliances And Wellness Based On Wireless Sensors", AISEM Annual Conference, 2015 XVIII DOI: 10.1109/AISEM.2015.7066808 Publication Year: 2015 , Page(s): $1-4$

[15]. Li Kaicheng; Liu Jianfeng; Yue Congyuan; Zhang Ming "Remote power management and meter-reading system based on ARM microprocessor", Precision Electromagnetic Measurements Digest, 2008. CPEM 2008. Conference on, On page(s): 216 - 217

\section{BIOGRAPHIES}

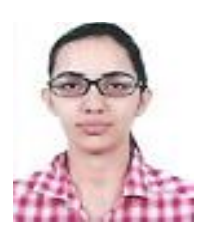

Monika Rana is currently Post Graduate student in Masters of Technology, Embedded Systems from ITM University, Gurgaon. She completed her B.Tech in Electronics and Communication Engineering from Banasthali University, Jaipur in 2013. Her area of interest is Embedded System Design and Real Time Systems.

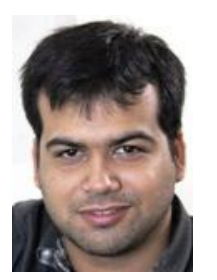

Prateek Bindra is working as an Asst. Professor in the Department of Electrical, Electronics \& Communication Engineering, ITM University, Gurgaon, (Haryana) India. He has received M.E. degree in Microelectronics and B.Tech. Degree in Electronics \& Communication Engineering. His main research interests are in device modeling, nanoelectronics and analog circuit design.

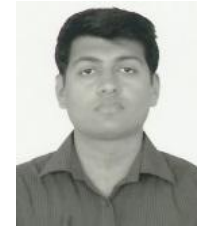

Manish Kumar Chauhan is pursuing Post Graduation in Masters of Technology, Embedded Systems from ITM University, Gurgaon. He completed his B.Tech in Electronics and Communication Engineering from Engineering College Ajmer, Rajasthan Technical University Kota in 2012. He has a keen interest in Real Time Operating System and Embedded Systems. 